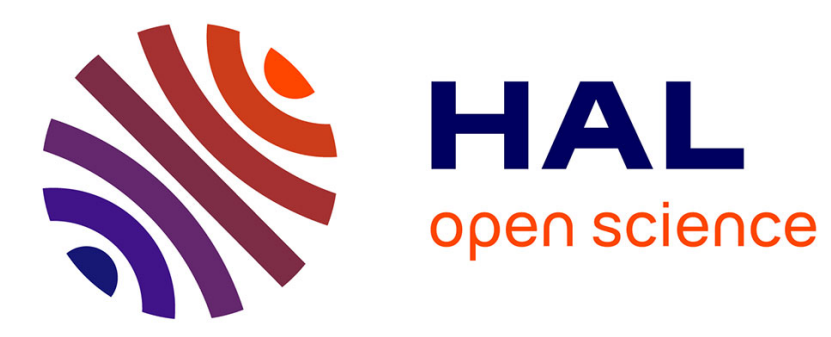

\title{
Material properties for process simulation
}

Z. Guo, N. Saunders, J.P. P Schillé, A.P. P Miodownik

\section{To cite this version:}

Z. Guo, N. Saunders, J.P. P Schillé, A.P. P Miodownik. Material properties for process simulation. Materials Science and Engineering: A, 2009, 499 (1-2), 10.1016/j.msea.2007.09.097 . hal-03349310

\section{HAL Id: hal-03349310 https://hal.science/hal-03349310}

Submitted on 20 Sep 2021

HAL is a multi-disciplinary open access archive for the deposit and dissemination of scientific research documents, whether they are published or not. The documents may come from teaching and research institutions in France or abroad, or from public or private research centers.
L'archive ouverte pluridisciplinaire HAL, est destinée au dépôt et à la diffusion de documents scientifiques de niveau recherche, publiés ou non, émanant des établissements d'enseignement et de recherche français ou étrangers, des laboratoires publics ou privés.

\section{(a)(1) $\$$}

Distributed under a Creative Commons Attribution - NonCommercial - NoDerivatives| 4.0 
Preprint of article published in Mat.Sci.Eng.A, 499, (2009), p.7

https://doi.org/10.1016/j.msea.2007.09.097

\title{
Material Properties For Process Simulation
}

\section{Z. Guo*, N. Saunders, J.P. Schillé, A.P. Miodownik}

Sente Software Ltd., Surrey Technology Centre, Guildford GU2 7YG, U.K.

\begin{abstract}
This paper reviews the recent developments in material property modelling and its applications in processing simulation. Many material properties needed by process simulation can now be readily provided, such as the solidification properties and high temperature stress-strain curves. The solidification properties are affected by changes in composition within the specification range of an alloy; such changes in properties then affect casting simulation results. The mechanical properties are calculated by considering two competing deformation mechanisms (dominated by either dislocation glide or dislocation climb), with automatic selection of the dominant mechanism. Sample calculations are given for a variety of engineering alloys, including steels, aluminum, titanium, and nickel-based superalloys. The material properties data calculated can now be passed directly into commercial computer-aided engineering (CAE) packages for casting and deformation simulation.
\end{abstract}

Keywords: Material properties; Process simulation; High temperature strength; Stressstrain curves; JMatPro

\footnotetext{
* Corresponding author: Tel: +44-(0)-1483-685475; fax: +44-(0)-1483-685472.
}

E-mail address: z.guo@sentesoftware.co.uk 


\section{Introduction}

Material data is a vital input for CAE process simulation packages based on finiteelement or finite-difference (FE/FD) analysis. Such data include physical, thermophysical and mechanical properties, all as a function of temperature. Traditionally such data are gathered from experimentation, which has significant disadvantages in that not all of the required data are readily available and, in particular, measurement of high temperature properties is not only expensive but time-consuming. It is therefore of no surprise that lack of material data has been a common problem for all FE/FD simulation packages. To overcome this problem and provide reliable and cost effective data for process simulation, computer-based models are required so that such properties can be readily calculated. A schematic diagram of the approach for processing modelling is shown in Fig. 1.

The present paper demonstrates the capabilities of computer software JMatPro [1] that is able to calculate the material data required in process simulation, which otherwise has to be measured through experiments such as dilatometry and Gleeble ${ }^{\circledR}$ testing. While detailed information on the development and validation of relevant models can be referred to Refs. $[2,3,4,5,6,7]$, this paper is focused on the application aspects of the material data calculated, concentrating on two areas. One is the calculation of physical and thermophysical properties critical to casting simulation. The other is the calculation of high temperature strength and stress-strain curves which are critical to deformation simulation.

\section{Physical and Thermo-Physical Properties}

Physical and thermo-physical properties are critical parameters for casting simulation. JMatPro's ability to model these properties has been well documented in previous 
published work for various metallic systems $[3,4,5]$. The properties that can be modelled include: density, molar volume, thermal expansion coefficient, Young's, bulk and shear modulii, Poisson's ratio, thermal conductivity and diffusivity, electrical conductivity and resistivity, all are provided for each available phase when necessary.

This section examines how changes in composition within the specification range of an alloy may affect its properties during solidification, and how casting simulation results are consequently influenced [7]. An aluminium alloy A319 is taken as an example here. The compositions of various A319 alloys are given in Table 1. Variations in elements Si, $\mathrm{Cu}$ and $\mathrm{Zn}$ were considered and the freezing range calculated for the three alloys are also given in Table 1.

Fig. 2 shows fraction solid vs. temperature plots calculated for the three A319 alloys. As might be expected, with increasing $\mathrm{Cu}$ and $\mathrm{Si}$ the freezing range decreases. Higher levels of Si also increases the amount of silicon eutectic and reduces the range of primary aluminum phase. The change in density during solidification for the three alloys shown in Fig. 3 demonstrates that total density change can be strongly affected by the fraction solid behaviour within specification.

The material property data calculated has been used as direct input to casting simulation software MAGMASOFT ${ }^{\circledR}$ and PROCAST ${ }^{\circledR}$. How changes in material properties due to variation in composition may affect the results of casting simulation is demonstrated here using MAGMASOFT ${ }^{\circledR}$. The component is a cylinder head typically made of A319 alloy via gravity casting [8]. Fig. 4 shows the calculated local solidification time for various A319 alloys. Local solidification time is one of the most used criteria that can show potential regions for defects, which are often isolated maximum heights in the casting. There are no isolated maxima shown in Fig. 4. However, it can be seen that 
solidification behaviour has been significantly altered through changing the composition, which has a subsequent significant impact on the feeding behaviour in critical regions of the cast. The calculated feeding percentage for various A319 alloys is shown in Fig. 5, which allows the user to determine the quality of feeding of the casting, which in turn will allow the user to see potential areas where porosity may occur. It can be seen that for the alloy A319 at high specification the feeding result shows no problems in the displayed region, while the average and low compositions indicate potential problems with porosity. This can be explained by the fact that for the best case, the local solidification time in the critical area is increased, leading to better liquid flow and hence a lower susceptibility to defects from poor feeding.

\section{High Temperature Strength and Stress-Strain Curves}

In addition to thermo-physical properties, thermo-mechanical processing simulation requires important mechanical properties such as high temperature strength and stressstrain curves (or flow stress curves). CAE simulation packages normally provide a range of constitutive equations that describe stress as a function of temperature, strain and strain rate, and the choice of the equations used can significantly affect the simulation results. Not only does the user have to decide which equations to use, but also he has to determine the values of the material parameters in those equations.

Examination of alternative constitutive equations shows that some of them are based on empirical observations of phenomena measured at macro level, i.e. the shape and form of the stress/strain curve, while others are motivated by micro-mechanical considerations [9], i.e., the development of those equations used to describe materials' behaviour is not based on the underlying mechanisms of material deformation. 
The present section looks at this problem from the viewpoint of modelling the actual mechanisms that may operate during deformation of alloys. In essence the problem is to define the flow stress as a 3-dimensional surface, which has as its axes temperature, strain and strain rate, i.e.

$$
\sigma=\mathrm{f}(\mathrm{T}, \dot{\varepsilon}, \dot{\varepsilon})
$$

The strength-temperature plot (fixed strain and strain rate) and stress-strain curve (fixed temperature and strain rate) are two special cases of eq.1 when two of the three variables are fixed.

Generally speaking, room temperature strength decays monotonically with increasing temperature until the point where it enters into a temperature regime whereby there is a sharp fall in strength and flow stress becomes much more strongly dependent on strain rate. This sharp drop in strength is due to a change of deformation mechanism dominated by dislocation glide (DDG) at low temperatures to one dominated by dislocation climb (DDC) at higher temperatures, where the latter is usually the controlling mechanism for creep. JMatPro employs different strength models to account for these two different mechanisms and whichever has the lower resistance to deformation controls the final strength of the alloy $[3,10,11]$. The two regions are clearly shown in Fig. 6, using titanium alloy IMI 318 (equivalent to Ti-6Al-4V) as an example, where good agreement with experimental data is observed. To further validate the models, strength calculations vs. temperature were carried out for a wide range of commercial Ti-alloys and comparison against experimental values is shown in Fig. 7.

The change of deformation mechanism from DDG to DDC with increasing temperature is a common feature for most, if not all, of the engineering alloys. Fig. 8 shows the yield stress of two Ni-based Superalloys, one precipitation hardened by $\gamma^{\prime}$ phase 
(Nimonic 105) and the other a solid solution alloy (Nimonic 75). The transition where sudden softening occurs is correctly predicted, as the loss of strength of Nimonic 105 as the $\gamma^{\prime}$ phase dissolves. To emphasise the predictive capability of the model, the calculated yield stress of twenty-two commercial superalloys as a function of temperature between room temperature (RT) and $1000^{\circ} \mathrm{C}$ is shown in Fig.9.

Fig. 10 shows a similar plot for various stainless steels, including austenitic, ferritic and duplex types. Yield stress as a function of strain rate has also been calculated for a 316 stainless steel at strain rates of $0.0001,0.01$ and $1 \mathrm{~s}^{-1}$ and is shown in Fig. 11 . The switch of deformation from DDG to DDC is clearly observed and is substantially displaced as a function of strain rate. However, even at a strain-rate of $1 \mathrm{~s}^{-1}$, creep is still the dominant mechanism above $1000^{\circ} \mathrm{C}$. Of particular interest is that the strain rate dependency in the creep controlled regime is substantially greater than in the DDG regime. For example at $1100^{\circ} \mathrm{C}$, the yield stress increases by almost a factor 4 between 0.0001 and $1 \mathrm{~s}^{-1}$, in comparison yield stress in the DDG region is rather insensitive to strain rate.

The switch of deformation mechanism from DDG to DDC with increasing temperature that is seen in the yield stress (or $\sigma_{0.2}$ ) vs. temperature plots corresponds to the flow stress at a small fixed strain. However, we are also interested in flow at much greater strains and it is interesting to observe what may happen as strains are greatly increased, for example in a stress/strain curve. In this case we see that it is possible for deformation to start in the DDG region, with significant work hardening. However, at a critical strain $\left(\varepsilon_{\mathrm{t}}\right)$ the strength may reach a level where creep controlled flow is weaker, and deformation will continue by creep. This is shown schematically in Fig. 12. 
The procedures for the calculation of stress-strain curves in the DDC and DDG regions have been described in previous work Ref. [12] and Ref. [13], respectively and Fig.13 shows a comparison plot of calculated and experimental stress-strain curves for a medium carbon steel (strain rate $0.1 \mathrm{~s}^{-1}$ ) at elevated temperatures. The calculated stress-strain curves, which include a transition between deformation mechanisms agree rather well with experiment. It is noted that flow softening is often suggested to be due to the recovery and/or recrystallisation processes. However, as is clearly shown here, flow softening can be a natural result of the transition from DDG to DDC deformation mechanism.

Depending on the alloy type, temperature and strain rate regime, $\varepsilon_{t}$ can be quite different. For a given alloy, higher temperatures and slower strain rates may result in a smaller $\varepsilon_{t}$, while the DDG mechanism continues to dominate as stress monotonically increases with increasing strain, until fracture occurs. In high temperature regions, creep controlled deformation may be lower than the DDG controlled yield stress at all strains and flow is governed purely by creep. Fig. 14 shows the comparison of calculated and experimental stress-strain curves for nickel-based superalloy Inconel 718 at $1050^{\circ} \mathrm{C}$. In this case the DDG yield stress lies around $200 \mathrm{MPa}$ and only the $1 \mathrm{~s}^{-1}$ stress strain curve exhibits a transition between deformation mechanisms.

The flow stress curves of a titanium grade Ti-6Al-4V (ELI) are shown in Figs. 15 and 16 , corresponding to various strain rates at $950^{\circ} \mathrm{C}$ and various temperatures at strain rate $0.1 \mathrm{~s}^{-1}$, respectively. In all cases there is no DDG region, in good agreement with experimental observations. The predictive capability of the model in flow stress calculation for a wide range of Ti-alloys, which have been tested at various temperatures 
and strain rates, is demonstrated in Fig. 17. Similar accuracies between experiment and calculation have also been obtained for Ni-based superalloys [12] and stainless steels [14].

The proven accuracy of JMatPro in calculating high temperature strength and stressstrain curves demonstrates its ability in generating the flow stress data required for deformation simulation. The problem of choosing the right constitutive equation and assigning correct values to the material parameters involved has therefore been effectively removed. In addition, to make the calculated material data more easily used by process modellers, extra sub-routines have been written so that the data can now be organised in such a format that can be directly read by FE/FD simulation packages. Such linking has been successfully developed with casting, forging and heat treatment simulation packages and will subsequently be extended to welding simulation packages.

\section{Summary}

The paper has shown how the recent developments in materials properties modelling has been able to calculate a variety of material properties and behaviour for multi-component alloys. In particular, the paper has concentrated on solidification properties for casting simulation, and high temperature strength and stress-strain curves for deformation simulation. Links with many FE-based process simulation packages have been established successfully and the calculated material data can now be organised in such a format that can be directly read by such packages.

\section{References}

[1] http://www.sentesoftware.co.uk/biblio.html, A collection of free downloadable papers on the development and application of JMatPro, compiled by Sente Software Ltd., 
2007. (Most of the papers below authored by Saunders and Guo can be downloaded from this website.)

[2] N. Saunders, X. Li, A.P. Miodownik and J.P. Schille, in: Materials Design Approaches and Experiences, Eds. J.C. Zhao et al., TMS, Warrendale, PA, p. 185 (2001)

[3] N. Saunders, Z. Guo, X. Li, A.P. Miodownik and J.P. Schille: JOM Vol. 55, No.12, $60-65(2003)$

[4] N. Saunders, X. Li, A.P. Miodownik and J.P. Schille, in: Modelling of Casting, Welding and Advanced Solidification Processes X, Eds D. Stefanescu et al., TMS, Warrendale, PA, p. 669 (2003)

[5] Z. Guo, N. Saunders, A.P. Miodownik and J.P. Schillé: Mater. Sci. Eng. A413-414, 465-469 (2005)

[6] N. Saunders, Z. Guo, X. Li, A.P. Miodownik and J.P. Schille, in: Superalloys 2004, Eds K.A. Green et al., TMS, Warrendale, PA, p. 849 (2004)

[7] Z. Guo, N. Saunders, E. Hepp and J.P. Schillé, Modelling of material properties - A viable solution to the lack of material data in casting simulation, in: The $5^{\text {th }}$ Decennial International Conference on Solidification Processing, Sheffield, July 23-25, 2007

[8] E. Hepp, Private communication, MagmaSoft, 2007

[9] A. Söderberg and U. Sellgren, Modelling of Strain Hardening and Strain Rate Hardening of Dual Phase Steels in Finite Element Analysis of Energy-Absorbing Components, in: NAFEMS World Congress 2005, 17-20 May 2005, Malta

[10]Z. Guo, N. Saunders, A.P. Miodownik and J.P. Schillé, Materials Science Forum, Vols. 546-549, 1319-1326 (2007) 
[11]Z. Guo, N. Saunders, A.P. Miodownik and J.P. Schillé, Rare Metal Materials and Engineering, Vol. 35 Sup. 1, 108-111 (2006)

[12]N. Saunders, Z. Guo, A.P. Miodownik and J.P. Schillé, Modelling Material Properties and Behaviour of Ni and Ni-Fe Based Superalloys, in: Proceedings of 2005 Superalloys 718, 625, 706 and Derivatives, Eds. J. Groh, E. Loria, 2-5 October 2005, Pittsburgh, U.S.A.

[13]X. Li, A. P. Miodownik and N. Saunders, J. Phase Equilibria, Vol. 22, p. 247 (2001)

[14] Unpublished research, Sente Software Ltd., Guildford GU2 7YG, U.K., 2007 


\section{Captions of Tables and Figures}

Table 1: Composition and freezing range of three A319 alloys (wt.\%)

Fig. 1. JMatPro calculation provides an alternative to experimental measurement in providing the material data required for process simulation

Fig. 2. Calculated fraction solid vs. temperature for the three A319 alloys

Fig. 3. Calculated density vs. temperature for the three A319 alloys

Fig. 4. Calculated local solidification time for various A319 alloys

Fig. 5. Calculated feeding/porosity for various A319 alloys

Fig. 6. Comparison between experimental and calculated yield stress for titanium alloy IMI $318($ Ti-6Al-4V).

Fig. 7. Comparison between experimental and calculated yield stress for various Ti-alloys between RT and 700C.

Fig. 8. Comparison between experimental and calculated yield stress for Nimonic 75 and 105 as a function of temperature.

Fig. 9. Comparison between experimental and calculated yield stresst for various wrought nickel superalloys and pure Ni between $\mathrm{RT}$ and $1000^{\circ} \mathrm{C}$.

Fig. 10. Comparison between experimental and calculated yield stress for various stainless steels between $\mathrm{RT}$ and $900^{\circ} \mathrm{C}$.

Fig. 11. Calculated yield stresses for a 316 stainless steel as a function of temperature at various strain rates. 
Fig. 12. Change of deformation mechanism from DDG to DDC in a high temperature stressstrain curve at the critical transition strain $\left(\varepsilon_{t}\right)$

Fig. 13. Comparison of calculated and experimental stress-strain curves at $0.1 / \mathrm{s}$ for a carbon steel at various temperatures

Fig. 14. Comparison of calculated and experimental stress-strain curves for a nickel-based superalloy Inconel 718 at $1050^{\circ} \mathrm{C}$

Fig. 15. Comparison between experimental and calculated flow stress curves for Ti-6Al-4V (ELI) at $950^{\circ} \mathrm{C}$ with various strain rates.

Fig. 16. Comparison between experimental and calculated flow stress curves for Ti-6Al-4V (ELI) at various temperatures with strain rate $0.1 / \mathrm{s}$.

Fig. 17. Comparison between experimental and calculated flow stress for various titanium alloys at various temperatures and strain rates. 
Table 1: Composition and freezing range of three A319 alloys (wt.\%)

\begin{tabular}{l|l|l|l|l|l|l|l|l|l}
\hline A319 & Si & $\mathrm{Cu}$ & $\mathrm{Mg}$ & $\mathrm{Mn}$ & $\mathrm{Zn}$ & $\mathrm{Fe}$ & $\mathrm{Al}$ & $\begin{array}{l}\text { Freezing } \\
\text { range }\left({ }^{\circ} \mathrm{C}\right)\end{array}$ & Remarks \\
\hline Low spec & 5 & 3 & 0.3 & 0.5 & 0.1 & 0.6 & bal. & $508-617$ & Lower limit specification \\
\hline Average & 6 & 4 & 0.3 & 0.5 & 0.3 & 0.6 & bal. & $505-607$ & Average composition \\
\hline High spec & 7 & 5 & 0.3 & 0.5 & 0.5 & 0.6 & bal. & $500-596$ & Upper limit specification \\
\hline
\end{tabular}




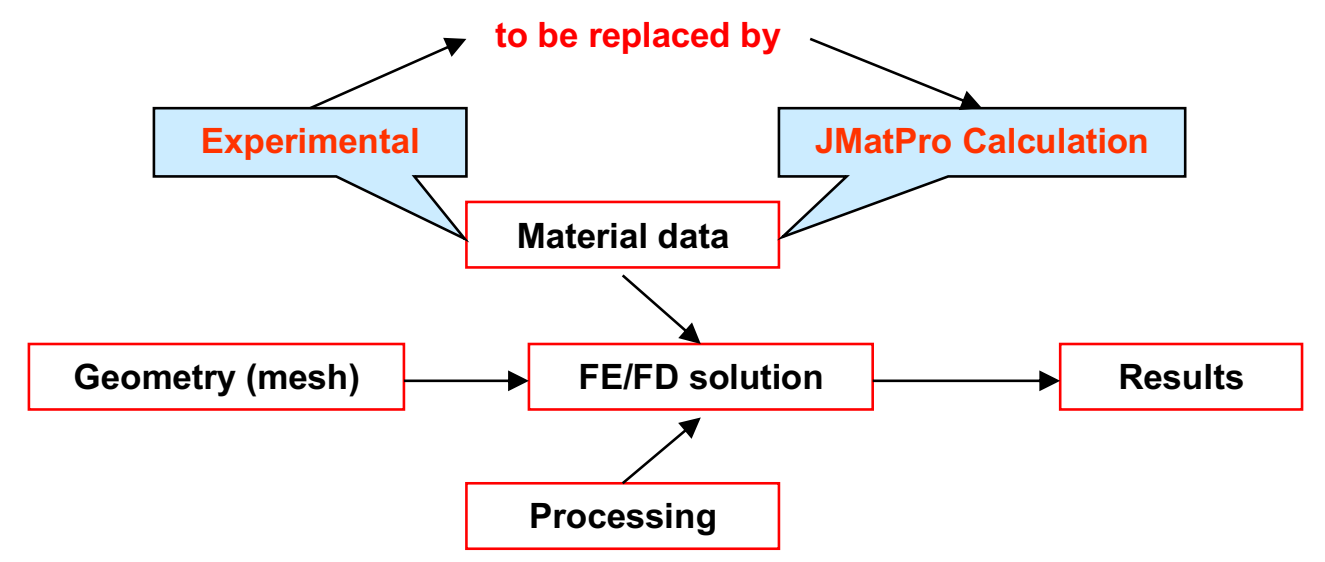

Fig. 1. JMatPro calculation provides an alternative to experimental measurement in providing the material data required for process simulation 


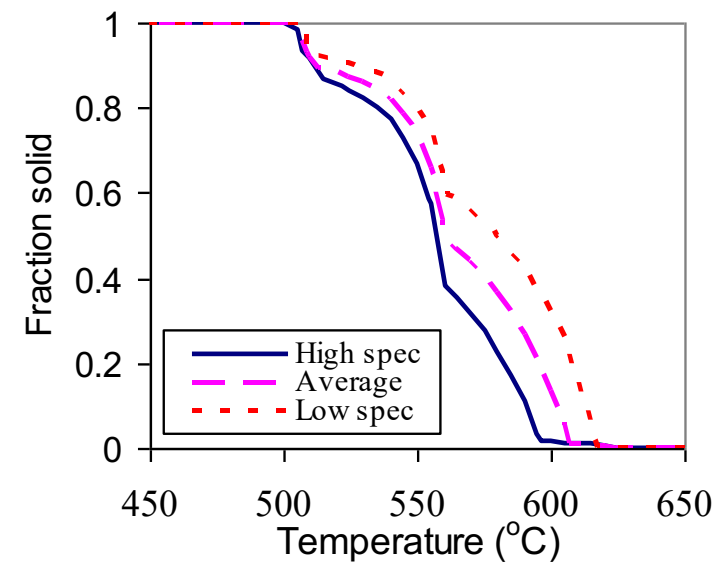

Fig. 2. Calculated fraction solid vs. temperature for the three A319 alloys

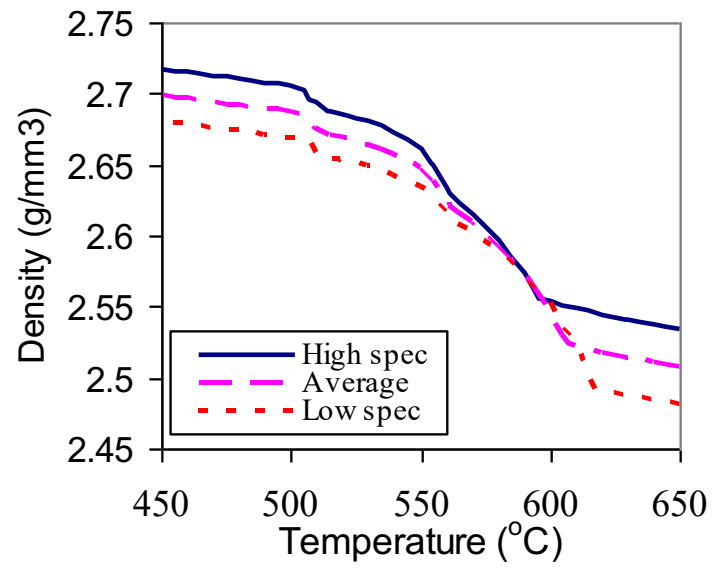

Fig. 3. Calculated density vs. temperature for the three A319 alloys 

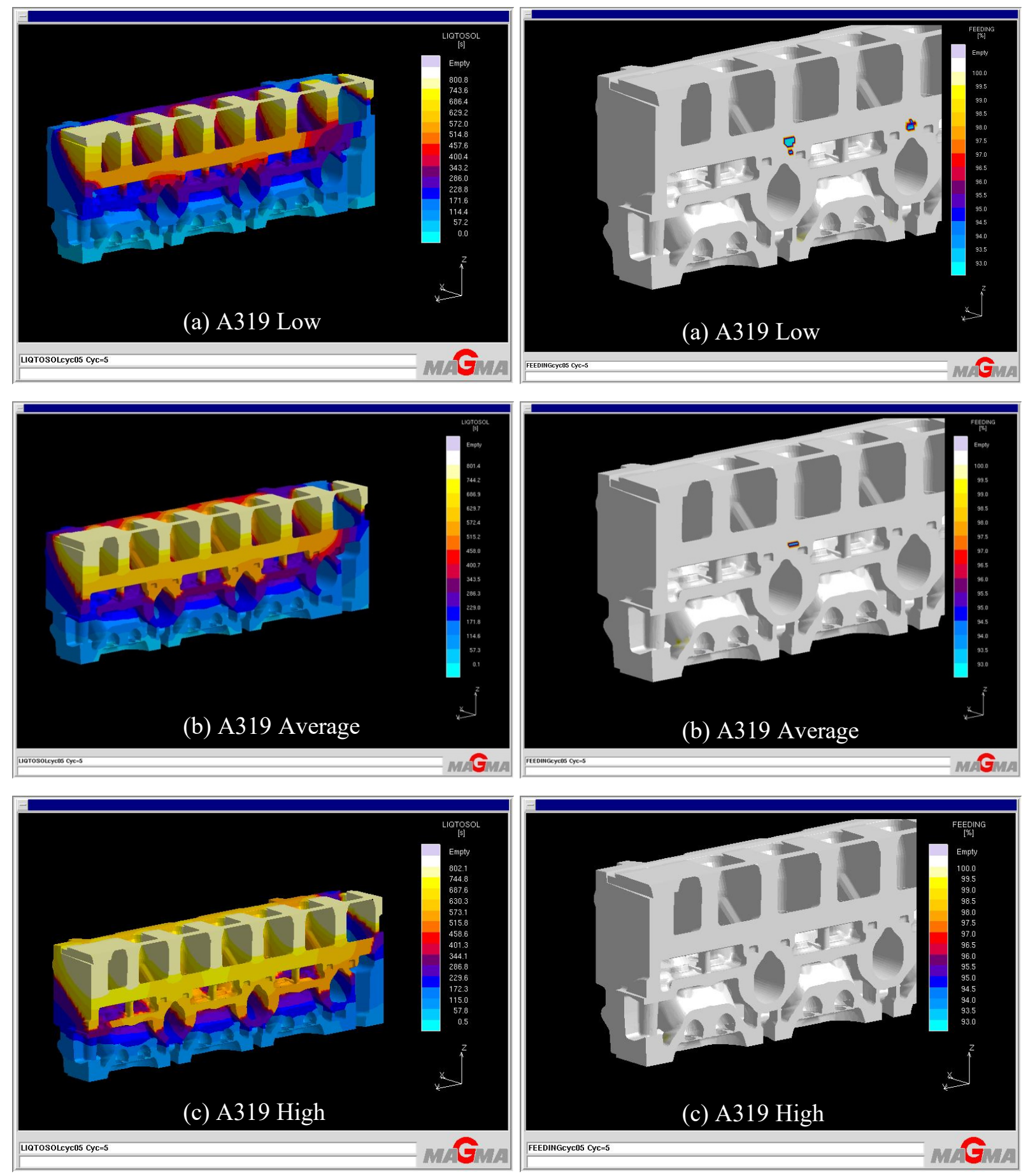

Fig. 4. Calculated local solidification time for various A319 alloys

Fig. 5. Calculated feeding/porosity for various A319 alloys 


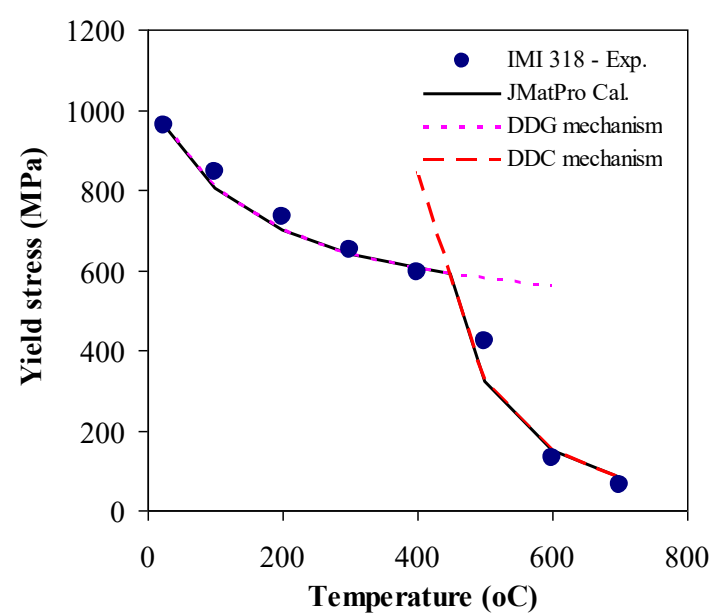

Fig. 6. Comparison between experimental and calculated yield stress for titanium alloy IMI 318 (Ti-6Al-4V).

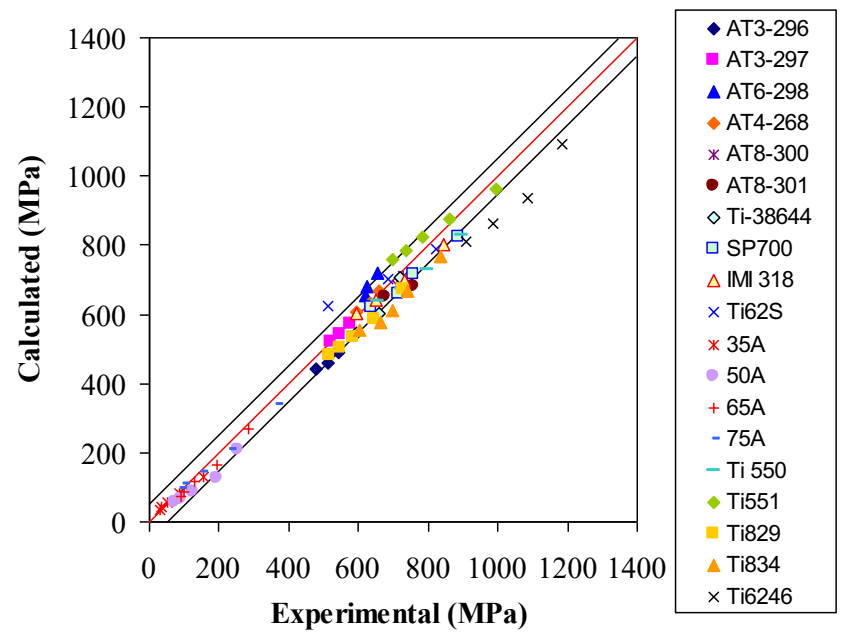

Fig. 7. Comparison between experimental and calculated yield stress for various Ti-alloys between RT and 700C. 


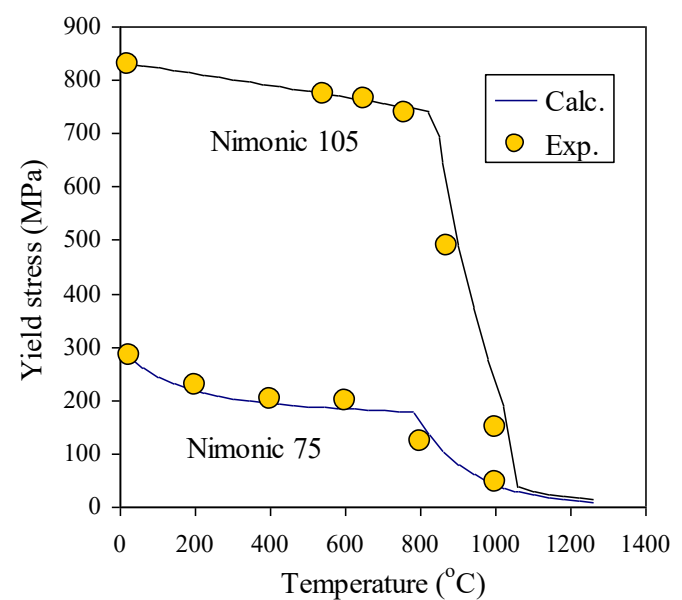

Fig. 8. Comparison between experimental and calculated yield stress for Nimonic 75 and 105 as a function of temperature.

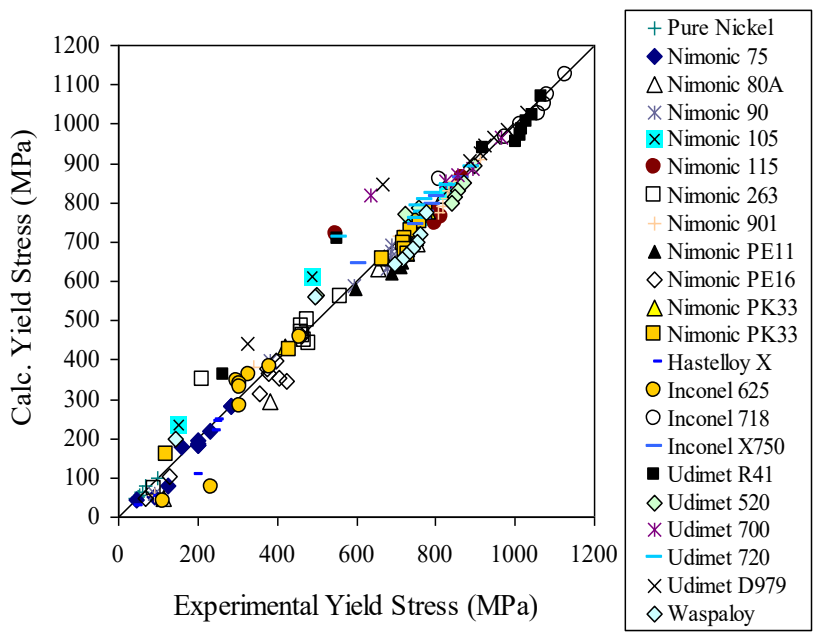

Fig. 9. Comparison between experimental and calculated yield stresst for various wrought nickel superalloys and pure Ni between RT and $1000^{\circ} \mathrm{C}$. 


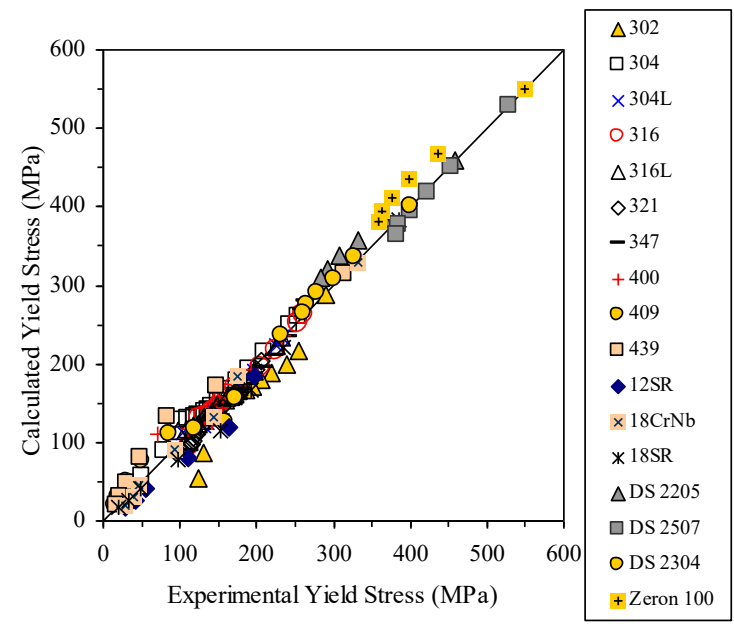

Fig. 10. Comparison between experimental and calculated yield stress for various stainless steels between RT and $900^{\circ} \mathrm{C}$.

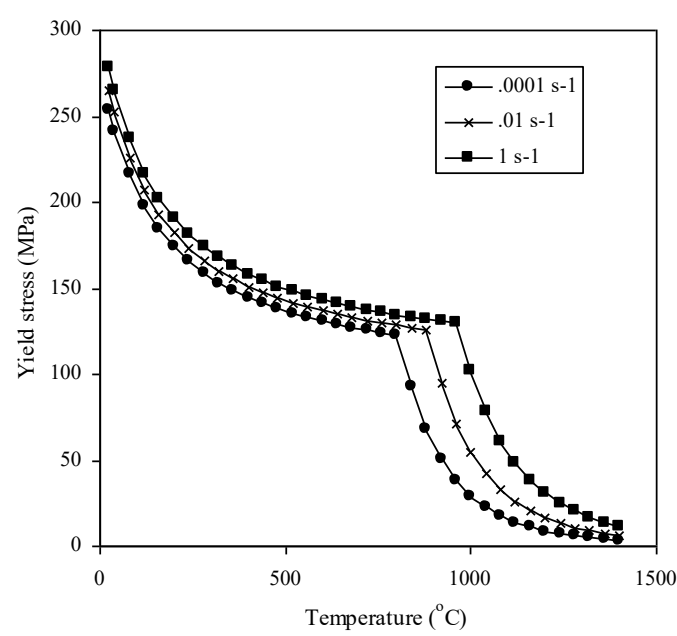

Fig. 11. Calculated yield stresses for a 316 stainless steel as a function of temperature at various strain rates. 


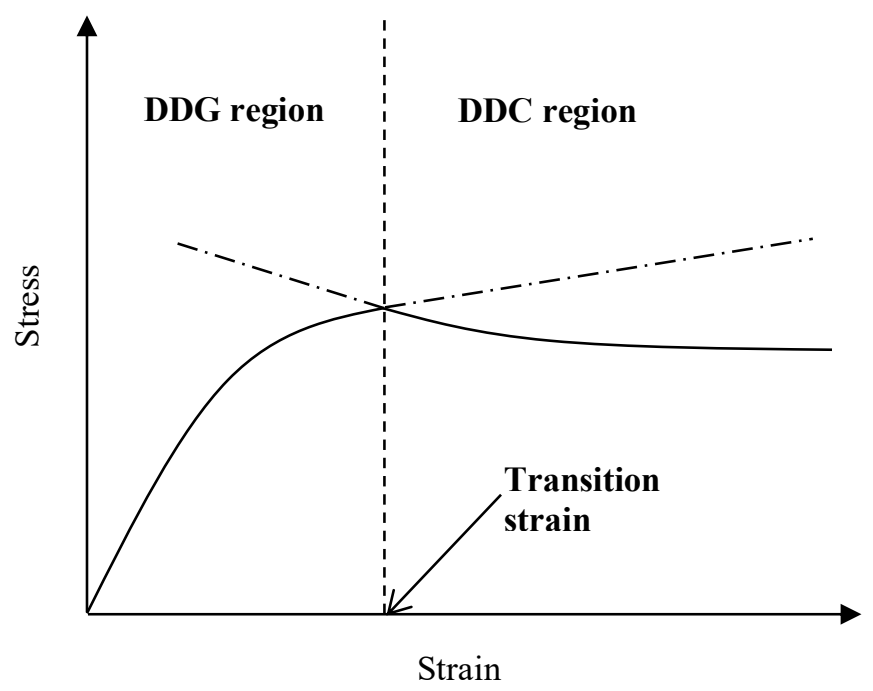

Fig. 12. Change of deformation mechanism from DDG to DDC in a high temperature stress-strain curve at the critical transition strain $\left(\varepsilon_{\mathrm{t}}\right)$ 


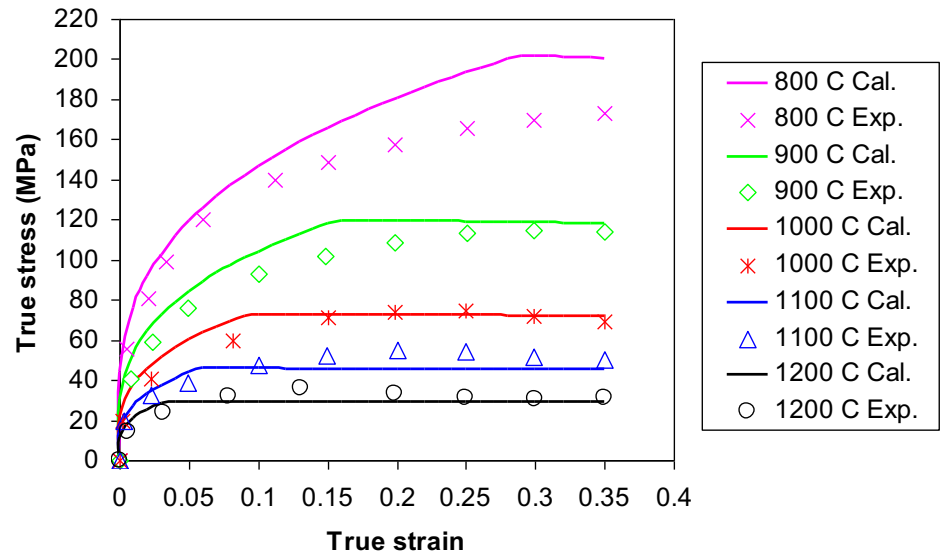

Fig. 13. Comparison of calculated and experimental stress-strain curves at $0.1 / \mathrm{s}$ for a carbon steel at various temperatures

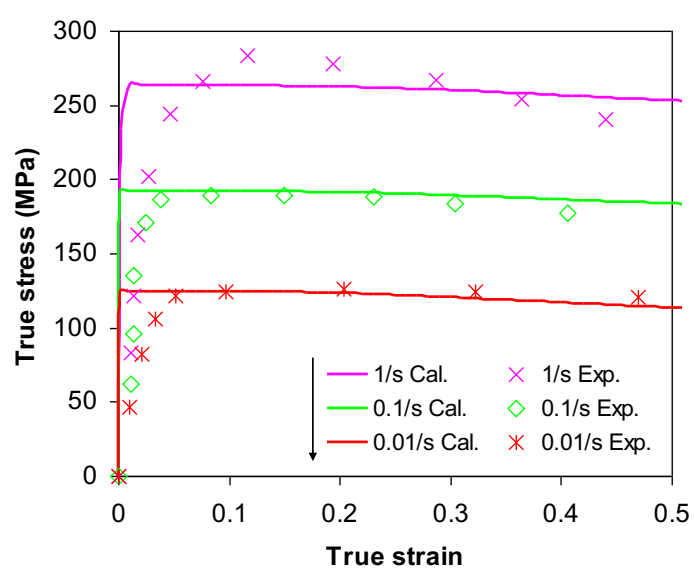

Fig. 14. Comparison of calculated and experimental stress-strain curves for a nickel-based superalloy Inconel 718 at $1050^{\circ} \mathrm{C}$ 


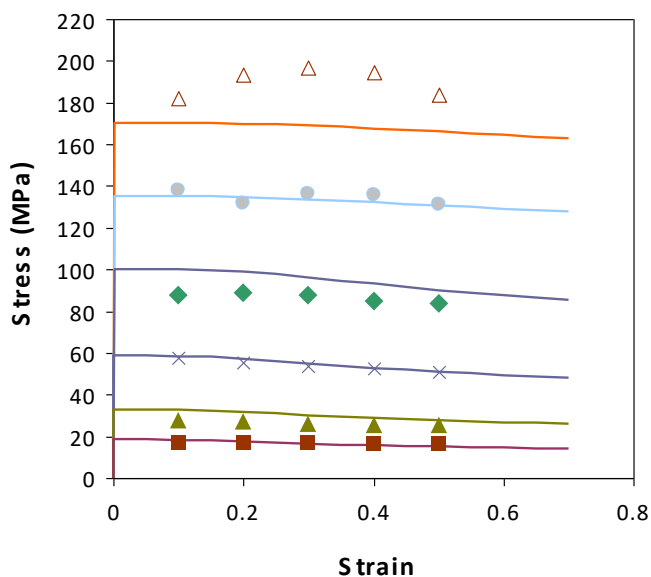

Fig. 15. Comparison between experimental and calculated flow stress curves for Ti-6Al-4V (ELI) at $950^{\circ} \mathrm{C}$ with various strain rates.

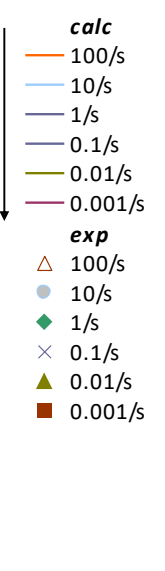

Fig. 16. Comparison between experimental and calculated flow stress curves for Ti-6Al-4V (ELI) at various temperatures with strain rate $0.1 / \mathrm{s}$. 


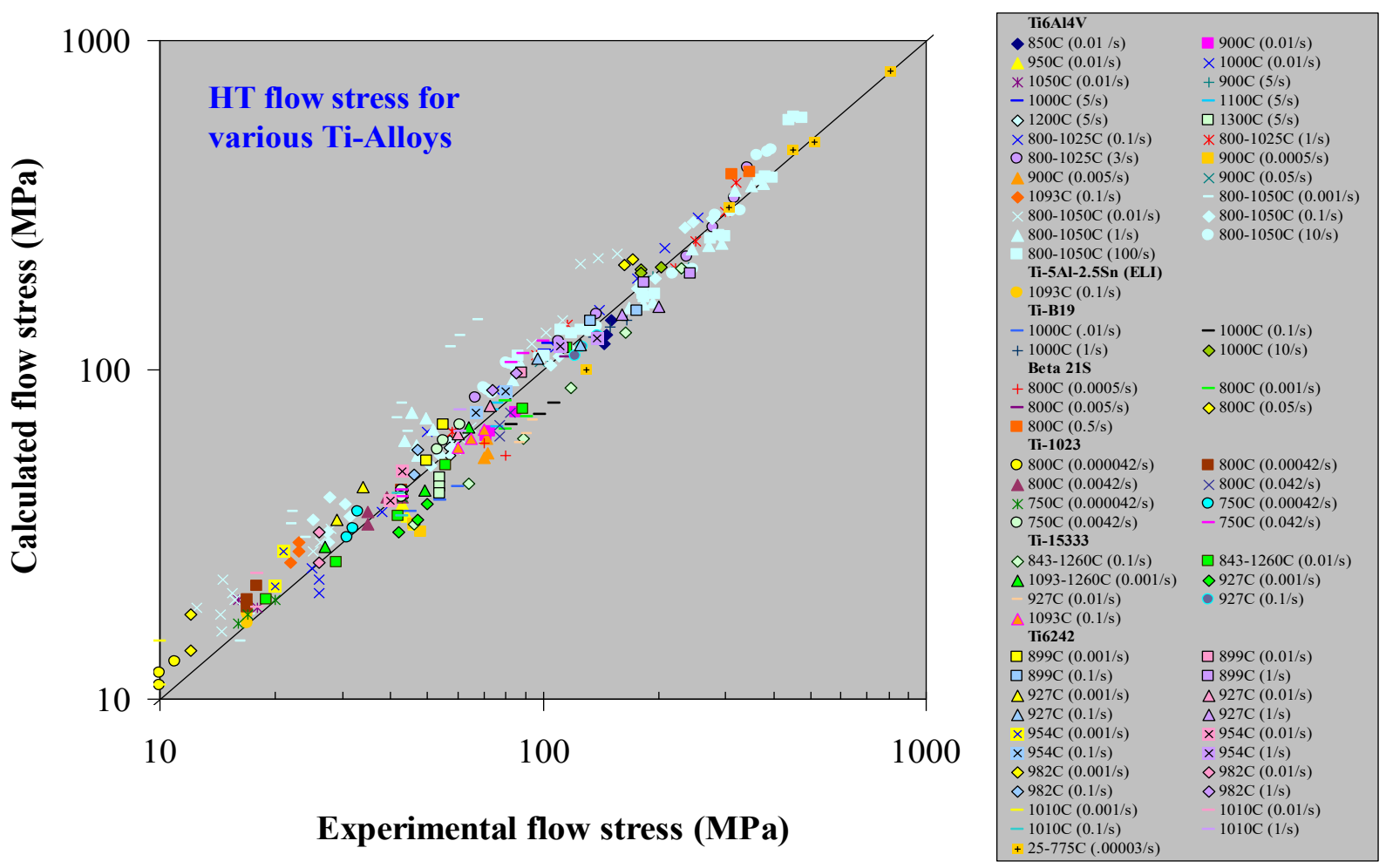

Fig. 17. Comparison between experimental and calculated flow stress for various titanium alloys at various temperatures and strain rates. 